\title{
An integrated cleanroom process for the vapor-phase deposition of large-area zeolitic imidazolate framework thin films
}

\author{
Alexander John Cruz ${ }^{\dagger, \hbar,}$, Ivo Stassen ${ }^{\dagger, \S}$, Mikhail Krishtab $^{\dagger, \S}$, Kristof Marcoen ${ }^{\ddagger}$, Timothée Stassin ${ }^{\dagger, \S}$, Sabina \\ Rodríguez-Hermida ${ }^{\dagger}$, Joan Teyssandier", Sven Pletincx ${ }^{\ddagger}$, Rhea Verbeke ${ }^{\dagger}$, Víctor Rubio-Giménez ${ }^{\perp, \dagger}$, Sergio Ta- \\ tay $^{\perp}$, Carlos Martí-Gastaldo ${ }^{\perp}$, Johan Meersschaut $^{\S}$, Philippe M. Vereecken ${ }^{\dagger, \S}$, Steven De Feyter ${ }^{\S}$, Tom Hauffman ${ }^{\ddagger}$, \\ and Rob Ameloot ${ }^{\dagger}, *$
}

$†$ Centre for Membrane Separations, Adsorption, Catalysis, and Spectroscopy for Sustainable Solutions (cMACS), Department of Microbial and Molecular Systems, KU Leuven - University of Leuven, Celestijnenlaan 200F, Leuven, 3001, Belgium

† Research Group of Electrochemical and Surface Engineering, Department of Materials and Chemistry, Vrije Universiteit Brussel, Pleinlaan 2, Brussels, 1050, Belgium

$\S$ imec, Kapeldreef 75, Leuven, 3001, Belgium

|| Division of Molecular Imaging and Photonics, Department of Chemistry, KU Leuven - University of Leuven, Celestijnenlaan 200F, Leuven, 3001, Belgium

$\perp$ Instituto de Ciencia Molecular, Universitat de València, Catedrático José Beltrán 2, Paterna, 46980, Spain

Robust and scalable thin film deposition methods are key to realize the potential of metal-organic frameworks (MOFs) in electronic devices. Here, we report the first integration of the chemical vapor deposition (CVD) of MOF coatings in a custom reactor within a cleanroom setting. As a test case, the MOF-CVD conditions for ZIF-8 are optimized to enable smooth, pinhole-free, and uniform thin films on full $200 \mathrm{~mm}$ wafers under mild conditions. The single-chamber MOF-CVD process and the impact of the deposition parameters are elucidated via a combination of in situ monitoring and $e x$ situ characterization. The resulting process guidelines will pave the way for new MOF-CVD formulations and a plethora of MOF-based devices.

Apart from their applications in catalysis, ${ }^{1}$ gas storage, ${ }^{2}$ and separation processes,${ }^{3}$ metal-organic frameworks (MOFs), with their unprecedented specific surface areas and chemical modularity, show tremendous potential for integration in microelectronics. ${ }^{4,5}$ As sensor coatings, their tunable composition and crystalline structure can be exploited for the selective adsorption of target molecules. ${ }^{6-9}$ The low dielectric constant resulting from their porosity makes MOFs prime candidates for high-performance insulators in future logic processors. ${ }^{10,11}$ To capitalize on the 
properties of MOFs in these areas, the development of a robust method to deposit thin and defect-free coatings is vital. This challenge has been a bottleneck for all microporous and crystalline materials tested in the context of electronic devices, as traditional wet synthesis procedures are incompatible with fabrication requirements due to contamination, corrosion, and limited control over the deposition process. ${ }^{4,12-14}$

Although crystalline coordination polymers have been deposited from gaseous precursors, the resulting materials have no measurable porosity. ${ }^{15-17}$ Most attempts to deposit MOFs via all-vapor-phase processes yielded nonporous or non-crystalline films unless subjected to post-deposition treatments such as crystallization in a reactive atmosphere. ${ }^{18-22}$ While these studies are valuable in providing insight into the chemistry needed to form MOFs on surfaces, it is necessary to develop an integrated process that can be extended to large-area substrates. We previously reported the chemical vapor deposition (CVD) of MOF thin films that are crystalline as-deposited, and porous after mild activation. ${ }^{12}$ This MOF-CVD process (Figure 1) starts with the deposition of a metal oxide layer, for instance through atomic layer deposition (ALD), by alternating self-limiting surface reactions of volatile reactants (e.g., diethylzinc and water). ${ }^{23}$ The MOF-CVD process relies on a previously reported solvothermal conversion of ALD oxides to $\mathrm{MOF},{ }^{24}$ but in the absence of solvents. When the ALD oxide coating is exposed to a vaporized linker under the right conditions, it undergoes a vapor-solid reaction to yield the desired MOF. As an example, ZIF-8, ${ }^{25}$ consisting of $\mathrm{Zn}(\mathrm{II})$ and 2-methylimidazolate (mIM), can be formed by exposing a $\mathrm{ZnO}$ precursor to a vapor of the protonated linker, HmIM (Figure S1). This method has been adopted to prepare gas separation membranes, sensors, and energy storage devices. ${ }^{26-29}$ In these approaches, tools commonly available in the wet chemistry lab (i.e., glassware and autoclaves) were used to perform the oxide-to-MOF conversion step. To become accessible to researchers from other fields and thus realize applications that cross subject boundaries, especially in microelectronics, the MOF-CVD process has to be implemented as a cleanroom unit operation and validated using the analysis tools common in such a setting.

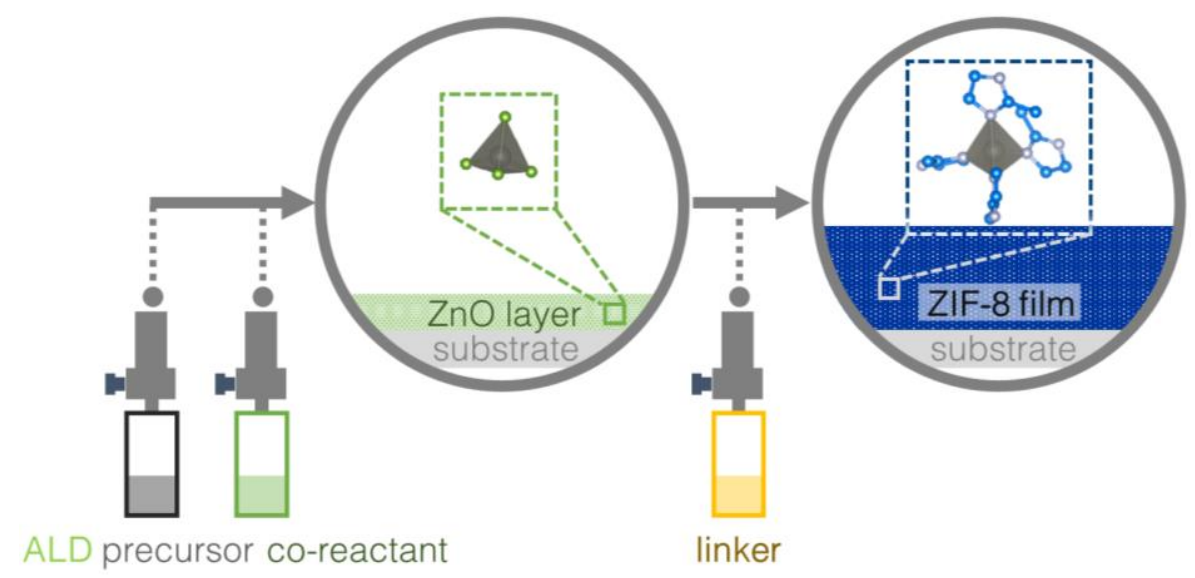

Figure 1. MOF-CVD process. Step 1) ALD of the metal oxide precursor: $\mathrm{Zn}\left(\mathrm{C}_{2} \mathrm{H}_{5}\right)_{2}(\mathrm{~g})+\mathrm{H}_{2} \mathrm{O}(\mathrm{g}) \rightarrow \mathrm{ZnO}(\mathrm{s})+2 \mathrm{C}_{2} \mathrm{H}_{6}(\mathrm{~g})$, followed by Step 2) exposure to the vaporized organic linker that initiates the vapor-solid reaction: $\mathrm{ZnO}_{(\mathrm{s})}+2 \mathrm{HmIM}_{(\mathrm{g})} \rightarrow \mathrm{H}_{2} \mathrm{O}$ $(\mathrm{g})+$ ZIF-8 (s). 
In this work, we realize both goals by developing an integrated MOF-CVD reactor and formulating a robust deposition protocol for ZIF-8 as a test case (Figure S2). By making use of in situ ellipsometry together with ex situ characterization techniques commonly used in microfabrication, the MOF-CVD mechanism is elucidated and critical deposition parameters are identified. The optimized deposition conditions are translated to $200 \mathrm{~mm} \mathrm{Si}$ wafer substrates, and the uniformity and the absence of pinholes are verified for the deposited coatings.

\section{Stages in the ZIF-8 MOF-CVD process}

Due to the low vapor pressure of $\operatorname{HmIM}\left(530 \mathrm{~Pa}\right.$ at $\left.125{ }^{\circ} \mathrm{C}\right),{ }^{30}$ this linker was supplied by flowing $\mathrm{N}_{2}$ through a heated bubbler-type sublimation vessel (Figure S3, see Methods). Other types of vapor sources for HmIM did not yield crystalline films, including a direct-vapor draw ALD bottle and a heated canister connected to an accumulator (Figure S4). When filling the sublimation vessel, the fresh HmIM powder is first heated and flushed with dry $\mathrm{N}_{2}$ $\left(100{ }^{\circ} \mathrm{C}\right.$ for $\left.30 \mathrm{~min}\right)$ to remove adsorbed moisture in the powder bed. A typical MOF-CVD process run for ZIF-8 consists of first depositing a $3 \mathrm{~nm}$ ALD $\mathrm{ZnO}$ film directly followed by exposure to HmIM vapor, in the same reaction chamber, under stopped-flow conditions. The cylindrical cross-flow MOF-CVD reactor chamber is $5 \mathrm{~mm}$ high, can hold substrates up to $200 \mathrm{~mm}$ in diameter, and is equipped with two independently controlled heating zones, for the substrate (chuck) and the reactor walls. The conversion of the $\mathrm{ZnO}$ film into a ZIF-8 layer is achieved only when a temperature gradient is applied between the reactor wall and the substrate, as further confirmed in a different reactor setup (Figure S5-6). This condition is analogous to polymer-CVD ${ }^{31,32}$ and likely associated with HmIM adsorption on the ZnO surface (Figure S7). The applied thermal gradient must strike a balance between the rate of oxide-to-MOF conversion and linker adsorption. In this reactor configuration and for a fixed reactor wall temperature $\left(150^{\circ} \mathrm{C}\right)$, a substrate temperature of $80^{\circ} \mathrm{C}$ was found to be optimal (vide infra).

Due to the porosity of ZIF-8, a pronounced thickness increase is expected when the MOF is formed from the dense $\mathrm{ZnO}$ layer. Time-resolved in situ ellipsometry data shows a sigmoidal thickness expansion of the oxide precursor as a function of HmIM exposure time (Figure 2a, Figure S8). A similar profile has been observed in in situ powder XRD, for the crystalline ZIF-8 content as a function of time during the solvent-free reaction of HmIM and $\mathrm{ZnO} .{ }^{12}$ From this MOF-CVD growth curve, three stages can be distinguished. Immediately after the introduction of HmIM, a limited thickness increase is observed (Stage A). Briefly after, a monotonic S-shaped rise in thickness is recorded (Stage B) followed by the formation of a continuous, $31 \mathrm{~nm}$-thick ZIF-8 film (Stage C). Quartz crystal microbalance (QCM) monitoring of the ZIF-8 MOF-CVD process displays a similar sigmoidal profile as a function of HmIM exposure time (Figure S9). The temporal mismatch of the mass gain and ellipsometry thickness evolution is likely due to the different heater configuration employed with the QCM setup, the dissimilar surface characteristics of the substrates (Figure S10), and the limitations of the technique in CVD. ${ }^{33,34}$ The oxide-to-MOF thickness 
expansion was found to be $10 \times$, thus lower than the 16-17 $\times$ expected for crystalline $\mathrm{ZnO}$ (hexagonal wurtzite). This difference can be attributed to the low-density ALD oxide deposited at a temperature of only $80{ }^{\circ} \mathrm{C} .{ }^{35,36}$ To quantitatively verify this hypothesis, several techniques were combined. Time-of-flight elastic recoil detection analysis (ToF-ERDA) reveals the presence of excess $\mathrm{O}$ in the layer, as would be expected for a low-density oxide due to the presence of hydroxyl groups (Figure S11). Rutherford backscattering and X-ray reflectivity measurements yielded a Zn density of $2.75 \pm 0.03 \times 10^{22}$ atoms cm$~^{-3}$ and a film density of $3.9 \mathrm{~g} \mathrm{~cm}^{-3}$. These values correspond respectively to $66 \%$ and $70 \%$ of what would be expected for ideal, single-crystal $\mathrm{ZnO},{ }^{37}$ and therefore explain the lower-than-expected thickness increase. X-ray photoelectron spectroscopy (XPS) confirmed that the low-temperature ALD ZnO has more Zn-OH moieties compared to a commercial ZnO nanopowder sample (Figure S12). These hydroxyl groups are advantageous for the solid-vapor reaction, as they increase the reactivity of the low-density oxide with the linker. ${ }^{12,38}$

a
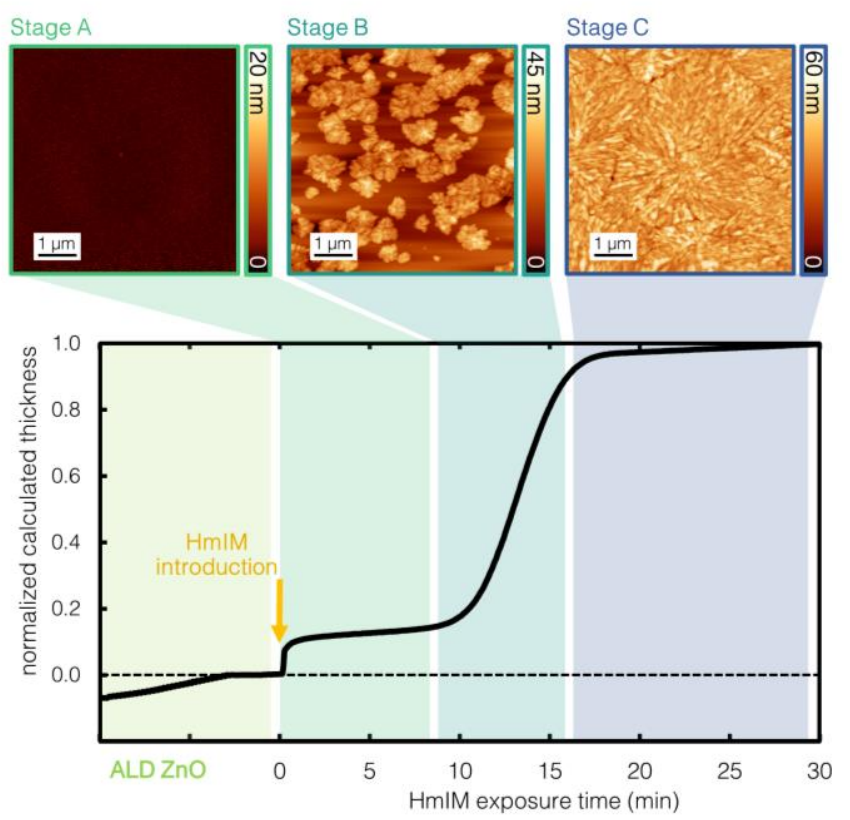

b

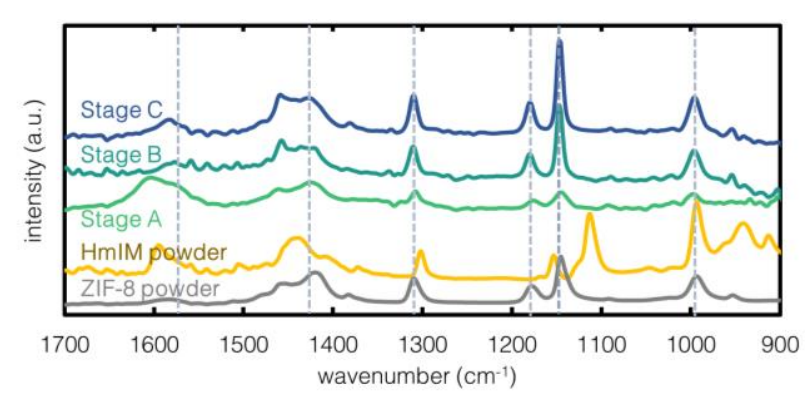

c

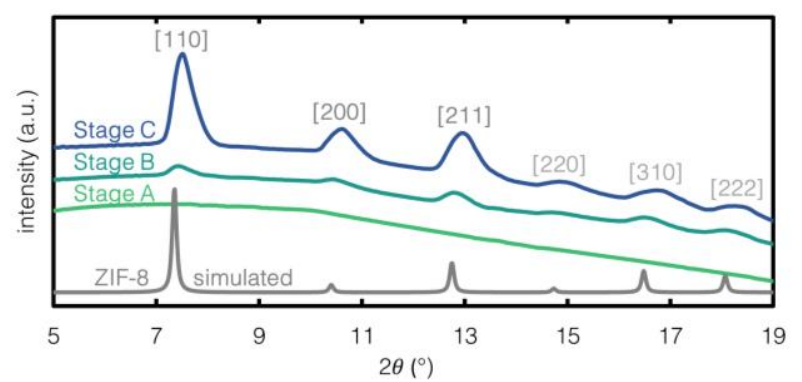

Figure 2. Monitoring ZIF-8 MOF-CVD. a, Time-resolved in situ ellipsometry data and corresponding AFM snapshots of the different growth stages. The surface roughness $\left(R_{R M S}\right)$ is calculated for a $6 \times 6 \mu \mathrm{m}^{2}$ probe area. Before HmIM is introduced at $\mathrm{t}=0 \mathrm{~min}$ (yellow arrow), $3 \mathrm{~nm}$ of ALD ZnO is deposited on the Si substrate. $\mathbf{b}$, Non-normalized ATR-FTIR spectra; commercial ZIF-8 (Basolite Z1200) and HmIM powders are included for reference. c, Synchrotron GI-XRD and simulated ZIF-8 diffraction patterns (CCDC code for ZIF-8: VELVOY).

To collect ex situ snapshots, the MOF-CVD process was stopped at selected time points by closing off the HmIM supply line and evacuating the reactor, thereby removing most of the physisorbed species, as shown by ellipsometry 
data (vide infra). AFM (Figure 2a) reveals a flat and featureless surface in Stage A, with a root-mean-square roughness $\left(R_{R M S}\right)$ of $0.3 \mathrm{~nm}$. The dispersed crystals that appear in Stage B eventually form a pinhole-free ZIF-8 film in Stage C with exceptional smoothness compared to typical MOF films $\left(R_{R M S}=4.4 \mathrm{~nm}\right) .{ }^{10,12,26}$ Fourier-transform infrared spectroscopy in attenuated total reflection geometry (ATR-FTIR, Figure 2b) reveals that the vibrational fingerprint of ZIF-8 is present in all stages, with growing intensity as a function of HmIM exposure time. This observation suggests that the coordination of $\mathrm{Zn}^{2+}$ to $\mathrm{mIM}$, and thus the reaction of $\mathrm{ZnO}$ with HmIM, starts soon after the linker vapor is introduced and is further incorporated in the layer throughout the CVD process. Nevertheless, synchrotron GI-XRD (Figure 2c, Figure S13) shows that crystallinity is only detected from Stage B onwards, simultaneously with the observation of crystallite nucleation in AFM.

\section{Insights in the ZnO-to-ZIF-8 transformation}

XPS confirms that the MOF-CVD ZIF-8 coating exhibits the $\mathrm{N}$ 1s signal characteristic of the linker, together with oxygen-containing groups on the top surface of the film. In addition, XPS allows for the differentiation of the MOF-CVD stages (Figure S14-15). To further understand the underlying chemistry and to validate the proposed mechanism for the ZnO-to-ZIF-8 conversion (Figure 3a), samples were analyzed at each growth stage by time-of-

flight secondary ion mass spectrometry (ToF-SIMS, Table S1, Figure S16). Depth profiling was performed by alternating sputter and analysis beams. The incorporation of $\mathrm{mIM}$ was probed as a function of film depth by measuring $\mathrm{C}_{4} \mathrm{~N}_{2}$-containing ion fragments $\left(\mathrm{C}_{4} \mathrm{H}_{6} \mathrm{~N}_{2}{ }^{+}, \mathrm{C}_{4} \mathrm{H}_{5} \mathrm{~N}_{2}{ }^{+}\right.$, and $\mathrm{C}_{4} \mathrm{H}_{7} \mathrm{~N}_{2}{ }^{+}$, Figure 3b). The Stage $\mathrm{A}$ film only contains linker near the surface with an unreacted $\mathrm{ZnO}$ precursor layer underneath. In Stage B, a more pronounced mIM signal extends deeper into the film. The signal for $\mathrm{Zn}-\mathrm{mIM}$ fragments $\left(\mathrm{ZnC}_{4} \mathrm{H}_{7} \mathrm{~N}_{2}{ }^{+}\right)$increases similarly as the oxideto-MOF conversion progresses (Figure S17). These observations, together with the data summarized in Figure 2, support the idea of a propagating reaction front during MOF-CVD ${ }^{12,38}$ and that a critical linker concentration must be incorporated in the oxide precursor to trigger nucleation. In Stage C, a constant mIM signal is recorded throughout the film thickness, as expected for a ZIF-8 layer. The reactive incorporation of the mIM linker early on in the MOF-CVD process is also evident from other observations. When the process is halted by evacuating the reactor in growth Stage A, the film thickness decreases only partially and does not fully revert to the $\mathrm{ZnO}$ precursor thickness (Figure 3c). In comparison, rapid and complete HmIM desorption is observed when the same procedure is repeated for bare Si substrates. In addition, partially converted samples removed in Stage B, after nucleation has taken place, show an increase in crystal surface coverage from $43 \%$ to $89 \%$ after storage on a lab bench for 30 days (Figure S18). This observation suggests that the linker reactively incorporated in the oxide precursor layer can give rise to further crystallization, albeit slowly, even at ambient conditions. 


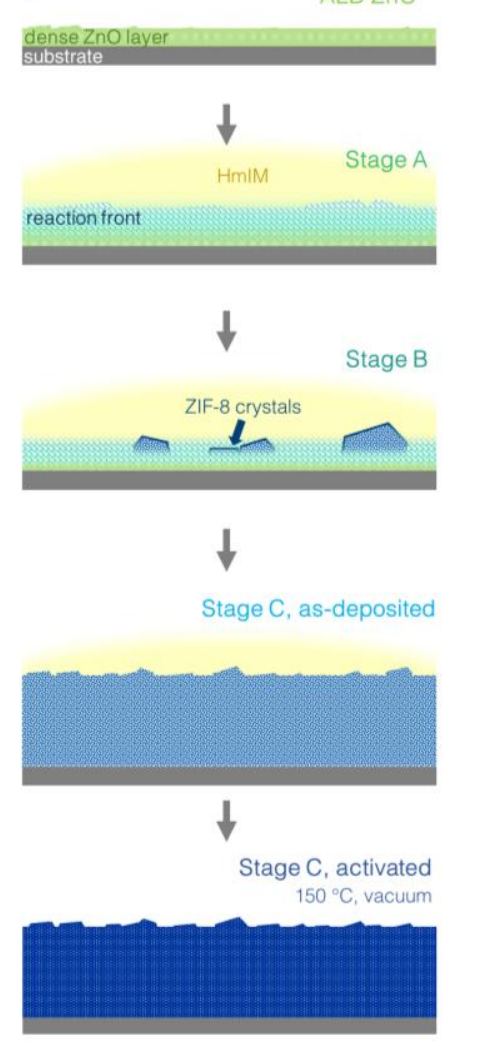

b

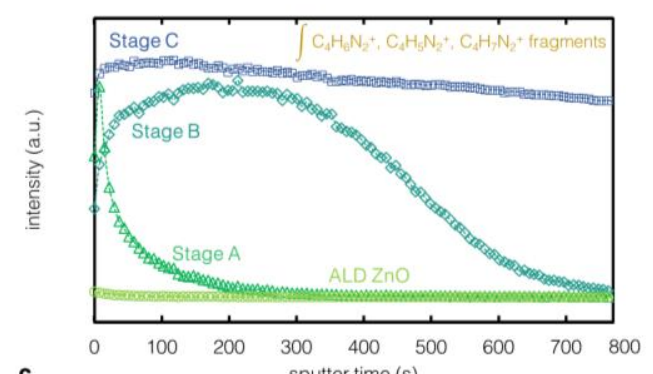

c

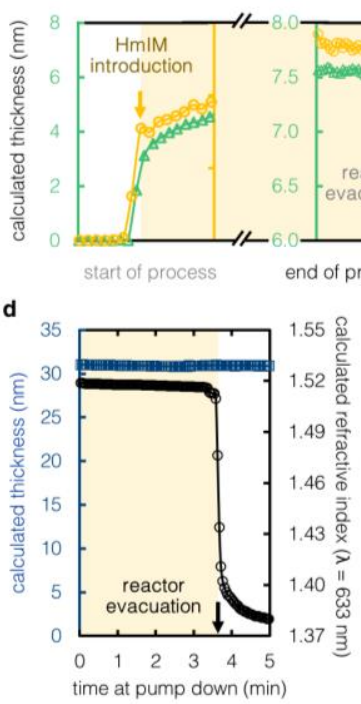

f

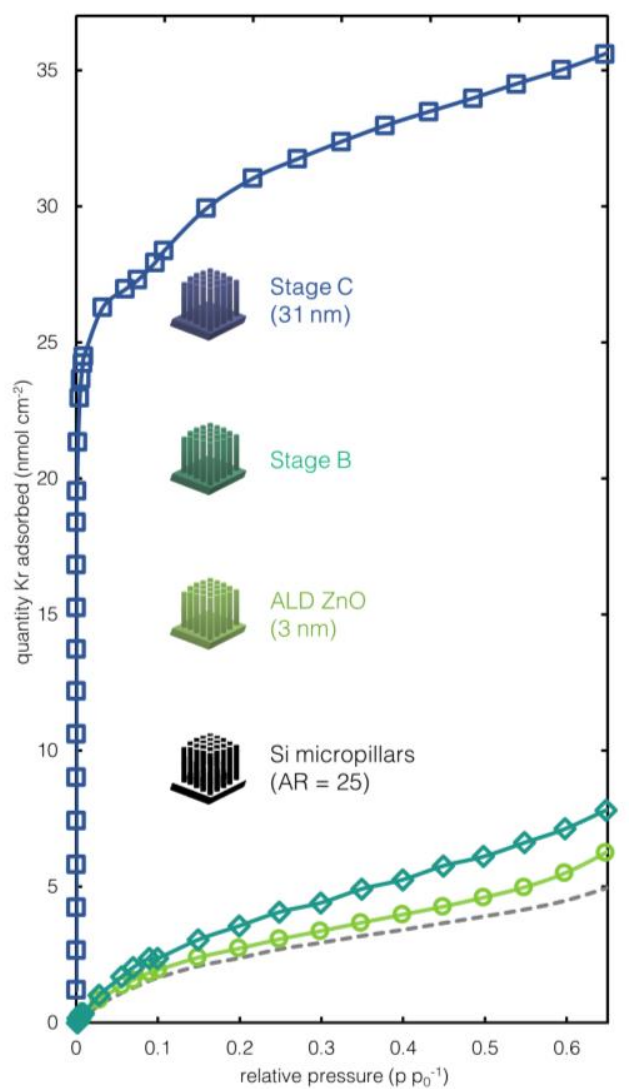

Figure 3. Insights in the ZnO-to-ZIF-8 transformation. a, Schematic representation of the MOF-CVD growth stages. b, ToF-SIMS depth profiles of mIM incorporated in the film at each growth stage. In situ ellipsometry profiles for c, HmIM desorption after reactor evacuation for the Stage A film with a control experiment on bare $\mathrm{Si}$, and $\mathbf{d}$, calculated thickness and refractive index profile during chamber evacuation at the end of the ZIF-8 MOF-CVD process. e, GI-XRD patterns of the asdeposited ZIF-8 film (dashed light blue) and the same sample after activation (solid dark blue). f, Kr physisorption isotherms for the films deposited on Si micropillars with an aspect ratio of 25. Stage C ZIF-8 (blue squares), Stage B (non-activated, dark green diamonds), ALD ZnO (light green circles) and uncoated substrate (dashed gray).

In the crystallized film, HmIM molecules both fill the pores and are adsorbed on the surface of the MOF film. Upon reactor evacuation, the weaker physisorbed molecules on the film surface are removed (Figure 3d). To free the pores of the remaining physisorbed $\mathrm{HmIM}$, the film was heated to $150{ }^{\circ} \mathrm{C}(15 \mathrm{~min})$ under vacuum in the reactor chamber, yielding a final refractive index of $1.33(\lambda=633 \mathrm{~nm})$, in agreement with previous reports. ${ }^{10,39}$ Activated and non-activated samples display different relative intensities for the [110] and [200] diffraction peaks (Figure 3e), correlated with HmIM pore filling. ${ }^{40-42}$ To determine the porosity of the MOF-CVD coatings before and after activation, Krypton physisorption isotherms were measured for ZIF-8 deposited on high-aspect-ratio micropillar arrays that have a surface area $26 \times$ higher compared to flat substrates (Figure 3f, Figure S19-20). The BrunauerEmmett-Teller (BET) specific surface area of the MOF-CVD ZIF-8 film, expressed per unit of substrate area, was found to be $35 \mathrm{~m}^{2} \mathrm{~m}^{-2}$. This sorption data corresponds to an average film thickness of $27 \mathrm{~nm}$, based on the calculated Kr BET surface area for ZIF-8 ${ }^{12,43}$ (Supporting Information, Section IV). The satisfactory agreement between 
this value and the experimental thickness obtained from ellipsometry $(31 \mathrm{~nm})$, together with the scaling of the porosity with the fraction of oxide converted to MOF, indicates that the conformal MOF-CVD ZIF- 8 coatings are of high quality (Table S2). In addition, $\mathrm{MeOH}$ isotherms measured for the films via ellipsometric porosimetry show an identical adsorption behavior as reported previously for ZIF-8 (Figure S21). ${ }^{10,44}$

\section{The role of humidity and oxide precursor thickness}

Prior in situ powder XRD experiments revealed a faster ZnO-to-ZIF-8 conversion in a humid environment ${ }^{12}$. To test if this behavior holds for thin films, MOF-CVD was performed at a relative humidity of $\sim 12 \%$. In situ ellipsometry data shows a substantial decrease in the time between HmIM introduction and ZIF-8 nucleation (Figure 4a, Figure S22), resulting in a rougher film $\left(R_{R M S}=21 \mathrm{~nm}\right)$ when compared to the standard $\left(R_{R M S}=4.4 \mathrm{~nm}\right)$, nonhumidified deposition conditions (Figure 4b, Table S3). Similar to the standard deposition conditions, an amorphous intermediate is formed that exhibits the IR vibrational bands characteristic of ZIF-8. Likewise, crystallinity is observed only when crystal facets become observable by AFM (Figure S23).

Kinetic crystallization models by Avrami ${ }^{45-47}$ and Gualtieri ${ }^{48}$, previously applied to MOF growth in solution ${ }^{49-}$ ${ }^{53}$, were employed to assess the impact of humidification (Supporting Information, Section VI, Table S4). These methods have also been used to describe the crystallization of thin films based on in situ ellipsometry. ${ }^{54,55}$ The exponent $n$, which relates to the dimensionality of crystal growth, is 4 for the Avrami and 3 for the Gualtieri model. These values imply that for both the standard and humidified conditions, the MOF crystallites grow in three dimensions which might indicate the mobility of the ZIF-8 building blocks at the crystallization front. The Gualtieri $b$ value of $\leq 15$ suggests that nucleation in both conditions is heterogeneous, ${ }^{48}$ as would be expected for a solventfree process. The Gualtieri growth rate $k_{g}$ increases approximately 20 -fold under humidified conditions, to the range previously found for ZIF-8 formation in solution. ${ }^{56}$ The facilitating role of water in the oxide-to-MOF conversion can be explained by the direct hydroxylation of $\mathrm{ZnO}^{36,57}$ as well as through the protonation of the linker, which subsequently reacts with $\mathrm{ZnO} .{ }^{58}$ Furthermore, water vapor enhances the mobility of MOF building blocks as also observed in other preparation routes in the absence of bulk solvents. ${ }^{59,60}$ This effect was also observed through increasing roughness of MOF-CVD ZIF-8 films with increasing relative humidity inside the chamber (Figure S24), for a fixed precursor thickness and HmIM exposure time. When a MOF-CVD ZIF-8 film without unreacted ZnO precursor was exposed a second time to HmIM in the presence of water vapor, the film roughness increased through recrystallization (Figure S25), in line with previous observations. ${ }^{61}$ In contrast, no recrystallization occurred when HmIM was introduced in the absence of moisture. 

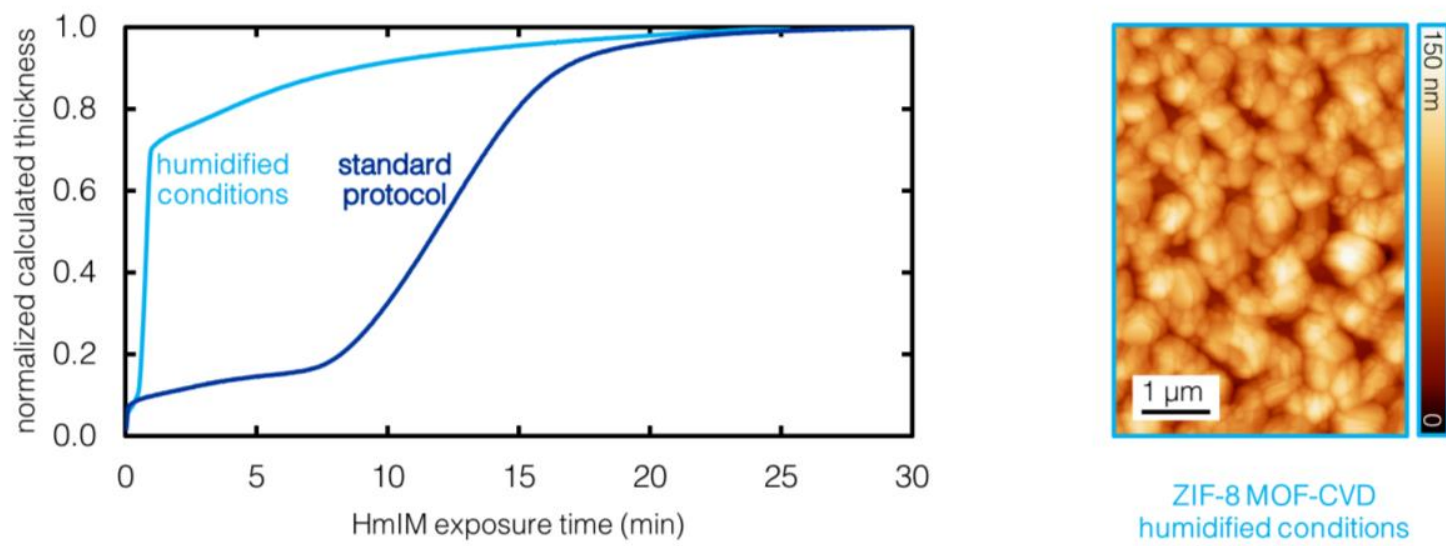

ZIF-8MOF-CVD humidified conditions

c
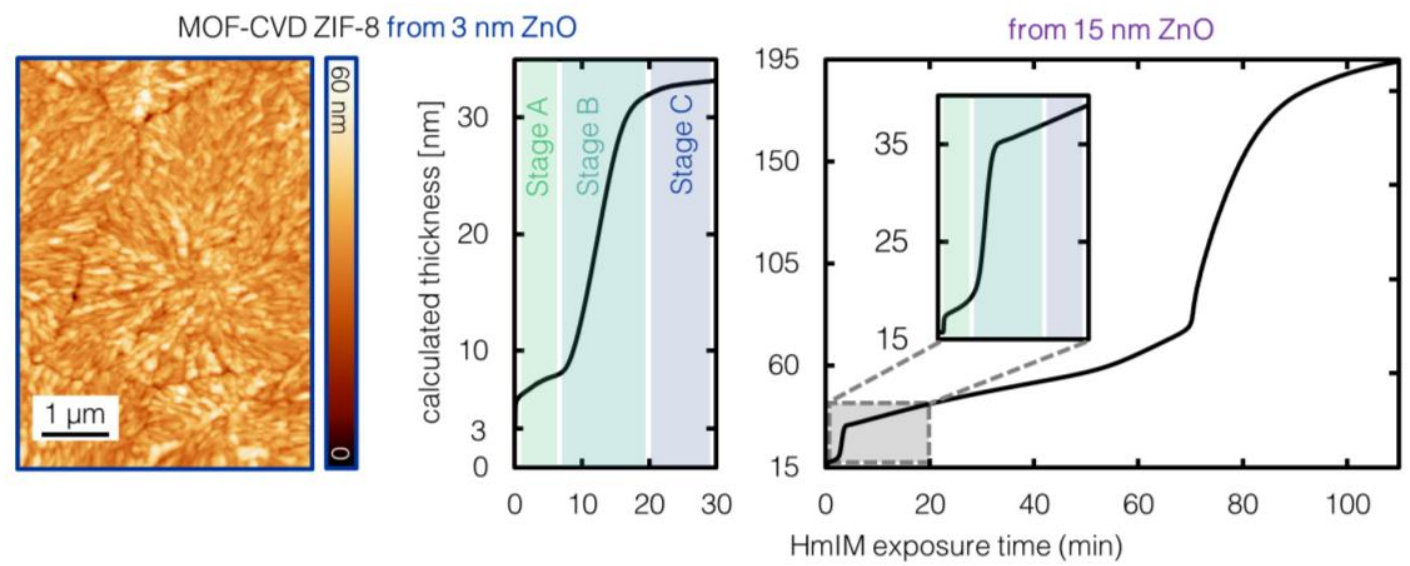

Figure 4. Influence of humidity and $\mathrm{ZnO}$ precursor thickness. a, ZIF-8 MOF-CVD process from $3 \mathrm{~nm} \mathrm{ZnO}$, as a function of HmIM exposure time for the standard (dark blue) and humidified (light blue) conditions. b, AFM image of the film deposited under humidified conditions $\left(R_{R M S}=21 \mathrm{~nm}\right)$. c, In situ ellipsometry data collected during the conversion of $3 \mathrm{~nm}$ and $15 \mathrm{~nm}$ ALD $\mathrm{ZnO}$ under non-humidified conditions.

The oxide-to-MOF transformations discussed so far started from a $3 \mathrm{~nm}$ ALD ZnO layer. These thin oxide precursor layers fully convert to a $\sim 30 \mathrm{~nm}$ ZIF-8 layer, as evidenced by a constant optical thickness and weight at the end of the vapor-solid reaction (Figure 2a, Figure S9), a steady mIM ToF-SIMS signal throughout the film (Figure 3b), elemental profiles measured with ToF-ERDA (Figure S26), and specific surface area in agreement with a fullyformed MOF layer (Figure 3f). For a $15 \mathrm{~nm} \mathrm{ZnO}$ layer, the in situ ellipsometry profile shows that initially, a ZIF8 layer of a comparable thickness $(\sim 35 \mathrm{~nm})$ is formed (Figure 4c, Figure S27). However, a second, more pronounced thickness expansion is observed after longer HmIM exposure time, corresponding to the reaction of the $\mathrm{ZnO}$ precursor underneath the initially formed ZIF-8 layer. Likely, the initially formed ZIF-8 layer slows down the accumulation of a critical HmIM concentration in the remaining oxide layer, acting as an additional mass transfer resistance layer, thus delaying further nucleation. This MOF layer also prevents the water formed by the reaction 
of $\mathrm{ZnO}$ and $\mathrm{HmIM}$ from rapidly escaping, leading to crystallization conditions similar to a humidified environment and resulting in rough ZIF-8 films $\left(R_{R M S}=38.4 \mathrm{~nm}\right)$. Nevertheless, thicker layers with an acceptable roughness can be deposited through a number of strategies: (1) 'supercycle' deposition of MOF-CVD stacks by alternating ZnO deposition and linker exposure, (2) planarization of thicker layers to bring roughness values to acceptable levels, and (3) engineering precursor morphology to improve the sub-surface accessibility to linker vapor (Supporting

\section{Information, Section VII, Figure S28).}

a
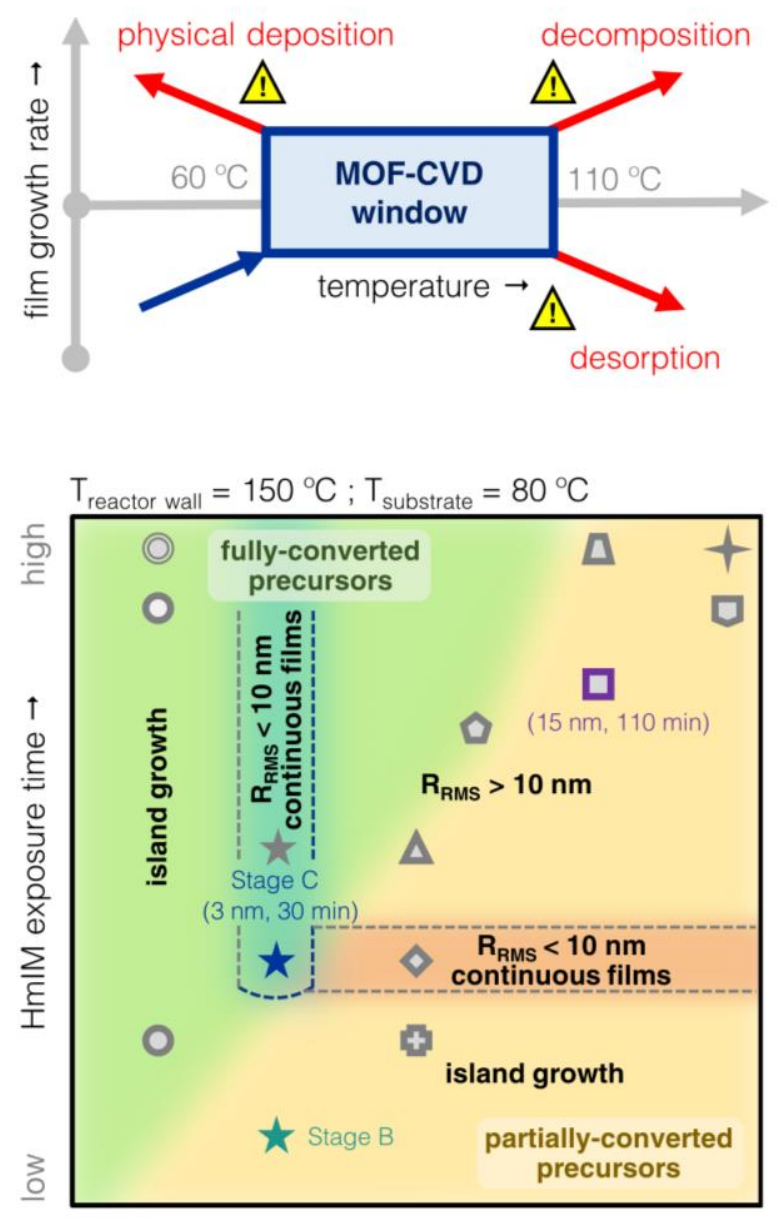

low starting $\mathrm{ZnO}$ precursor thickness $\rightarrow$ high b
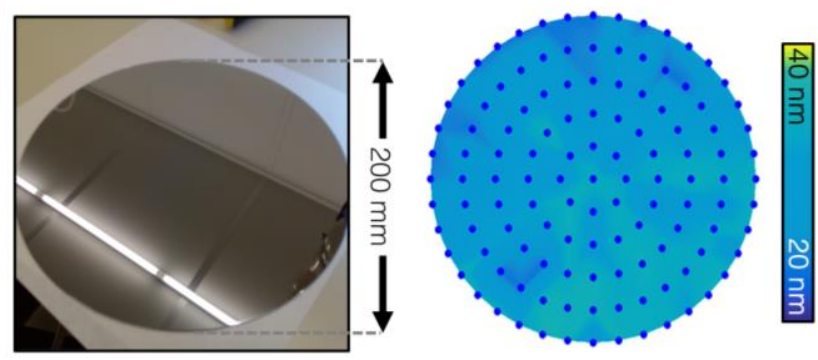

C

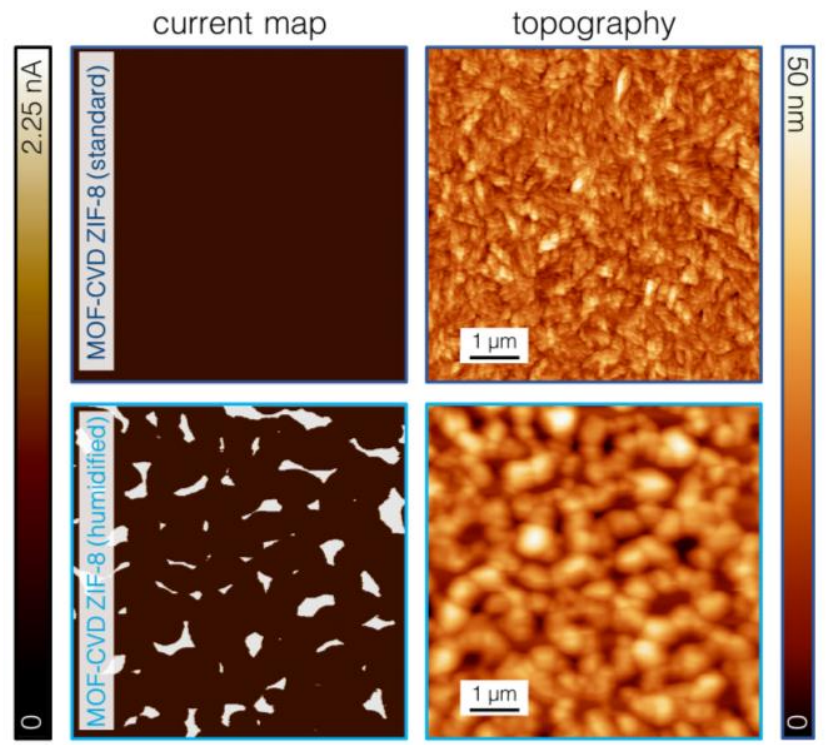

Figure 5. Full-wafer ZIF-8 MOF-CVD. a, MOF-CVD process chart for ZIF-8 that shows the impact of temperature, $\mathrm{ZnO}$ precursor thickness and HmIM exposure time (not to scale) on film morphology and extent of oxide-toMOF conversion, for the reactor used in this work at standard conditions ( $\sim 0 \%$ relative humidity). The conditions where $\mathrm{ZnO}$ precursor remains and is fully converted are indicated in yellow and green, respectively. $\mathbf{b}$, Photograph of a full $200 \mathrm{~mm}$ wafer with MOF-CVD ZIF-8 coating and the corresponding ellipsometry thickness mapping. c, Current and topography maps obtained by conductive AFM for MOF-CVD ZIF-8 films deposited under standard (top) and humidified conditions (bottom). The regions where current is detected correspond to pinholes in the layer. 


\section{Full wafer MOF-CVD}

The impact of process temperature, oxide thickness and ligand exposure time on the film morphology and the extent of precursor-to-MOF conversion can be represented in a MOF-CVD process chart (Figure 5a, Table S5). These parameters are correlated and strongly-interacting in the way they affect the resulting films. Substrate temperatures that are too low or too high result in rougher films and dispersed small crystallites, respectively (Figure S29). Moreover, for a specified substrate temperature, a minimum oxide precursor thickness is required to yield high-quality films. Furthermore, an optimal HmIM exposure time is needed to ensure complete $\mathrm{ZnO}$ conversion, yet avoid crystallite ripening. To show that these optimized deposition conditions for ZIF-8 can be translated to large substrates, experiments were performed on full $200 \mathrm{~mm}$ Si wafers. Aided by reactor simulations, we observed that a diffuser ring at the inlet of the MOF-CVD reactor chamber improves the exposure dynamics of the vapor precursors, yielding a more uniform flow pattern and film deposition (Figure S30-31), starting from a large-area Si substrate uniformly coated with ALD ZnO (Figure S32)The resulting transparent, mirror-like MOF coating has an average optical thickness of $31 \pm 3.5 \mathrm{~nm}$, as determined from a 100-point ellipsometry thickness mapping measurement (Figure 5b). Using the wafer as a back electrode, conductive AFM measurements were performed at different positions to check for pinholes in the film. Scans at a bias of $8.0 \mathrm{~V}$ (Figure 5c) confirm that the insulating MOF layer is pinhole-free at the nanoscale. As a negative control, the experiment was repeated for a MOF-CVD ZIF-8 sample deposited under humidified conditions. For this film, the pinholes that appear in between the crystallites as a result of ripening are clearly observed. Additionally, the pinhole-free nature of the optimized MOF-CVD ZIF-8 films was also confirmed on the millimeter scale using liquid metal contacts (Figure S33). Using the same deposition parameters as for ZIF-8, MOF-CVD runs using different metal oxides and linkers were performed to demonstrate the applicability of the process for other materials, namely ZIF-67 consisting of Co(II) and mIM, and ZIF-72 consisting of Zn(II) and 4,5-dichloroimidazolate (Figure S34-37, Table S6), paving the way for new MOFCVD formulations. ${ }^{62}$

\section{Conclusion}

In summary, we demonstrated for the first time the scale-up of the MOF-CVD process in a fully integrated reactor compatible with cleanroom standards. Through complementary in situ and ex situ techniques, the critical deposition parameters were identified for the case of ZIF-8 and the growth mechanism was elucidated. The optimized deposition conditions were successfully transferred to large-area substrates and characterized using the tools common in a cleanroom fabrication setting. The implementation of MOF-CVD as a standardized operation represents an important step in making this technique accessible to researchers from other fields and thus realize applications across traditional subject boundaries, especially in microelectronics. 


\section{Methods}

Substrates. Device grade, p-type, single-side polished, back-etched $200 \mathrm{~mm}$ Si wafers (Si-Mat, resistivity $=1$ $30 \Omega \mathrm{cm}^{-1}$, thickness $=381 \pm 25 \mu \mathrm{m}$ ) were used. Smaller pieces were cleaved and deposited with thin layers of Pt or $\mathrm{Au}$ as required for specific characterization techniques. Arrays of Si micropillars with a diameter and height of 2 and $50 \mu \mathrm{m}$, respectively, were produced by deep reactive ion etching (Bosch process). The pillars were separated $2 \mu \mathrm{m}$ apart in a triangular-pitch geometry and were patterned by standard photolithography procedures using 600 $\mathrm{nm} \mathrm{SiO} 2$ as a hard mask.

ZIF-8 MOF-CVD. All depositions were carried out in an ISO 6 cleanroom with controlled temperature $(21 \pm$ $\left.1{ }^{\circ} \mathrm{C}\right)$ and relative humidity $(40 \pm 5 \%)$ and were performed in a modified Savannah S-200 thermal ALD reactor (Veeco Instruments, Inc.). Prior to every run, a leak test was performed by measuring the rate of pressure rise when the reactor chamber is isolated from the vacuum pump and the gas supply lines. The pressure rate-of-rise threshold of $<50$ mTorr $\mathrm{min}^{-1}$ ensures a closed system.

ZIF-8 MOF-CVD Step 1 - ALD ZnO. The ZnO films were deposited with deionized water (DIW) and diethylzinc (DEZ, 97 \%, STREM) as precursors. Nitrogen (99.999\%) was the carrier and purging gas used, sourced from a header line in the cleanroom facility. The pulse and purge durations for the ALD precursors were set to $0.015 \mathrm{~s}$ and $5 \mathrm{~s}$, respectively. The reactor base pressure was $\sim 0.40$ mbar at an $\mathrm{N}_{2}$ gas flow of $20 \mathrm{sccm}$. This process resulted in a $\mathrm{ZnO}$ growth rate of $1 \AA$ cycle $^{-1}$ on Si substrates at $80{ }^{\circ} \mathrm{C}$ (Figure S38).

ZIF-8 MOF-CVD Step $2 a$ - HmIM delivery step standard protocol (non-humidified conditions). Start-up operation. Three heating zones were used as a preventive measure for HmIM condensation along the reactor lines. The bubbler-type sublimation vessel, initially supplied with freshly-ground HmIM (30 g, 99 \%, Sigma Aldrich), was set to $125^{\circ} \mathrm{C}$, while the outlet and supply lines of the bubbler and the connections to the MOF CVD reactor were fixed to $130^{\circ} \mathrm{C}$ and $135^{\circ} \mathrm{C}$, respectively. These lines were progressively heated in 30 -minute intervals to prevent clogging during start-up. Before the depositions, purging and drying sequences $\left(100^{\circ} \mathrm{C}, 30 \mathrm{~min}\right)$ were implemented to ensure the removal of air and moisture in the headspace of the bottle and the HmIM powder bed. HmIM delivery. The $\mathrm{N}_{2}$ flow was stopped and the outlet valve was closed to ensure controlled HmIM delivery and saturation (stopped-flow conditions) inside the reactor with an $\mathrm{N}_{2}$ bubbler pressure of 110 mbar. The substrate and reactor wall temperatures were set to $80^{\circ} \mathrm{C}$ and $150{ }^{\circ} \mathrm{C}$, respectively. HmIM precursor aging. a delay in nucleation occurs after prolonged use of the same HmIM batch (Figure S39-40), likely due to slower sublimation kinetics caused by HmIM particle growth (Figure S41-42). This occurrence is a consideration for process scale-up, to ensure a surface- 
saturating and sustained vapor flux. Industrial solutions exist for handling this difficulty in using solid precursors, including fluidization ${ }^{63}$ and solvent-assisted delivery. ${ }^{64}$

ZIF-8 MOF-CVD Step $2 b$ - HmIM delivery step humidified conditions. Immediately before dosing HmIM (described above as Step 2a), water was introduced by means of pulses, achieving $\sim 12 \%$ relative humidity in the reactor. This value was estimated by noting the pressure increase in the reactor after dosing, divided by the water saturation pressure at the substrate temperature $\left(80^{\circ} \mathrm{C}\right)$.

ZIF-8 MOF-CVD activation protocol. The recipe was terminated with an evacuation step and with the $\mathrm{N}_{2}$ flow maintained at $20 \mathrm{sccm}$. The dynamic vacuum was kept as the substrate temperature was ramped up and held briefly at $150{ }^{\circ} \mathrm{C}$ until a constant profile is recorded with in situ ellipsometry ( $\sim 10$ minutes). The activation protocol was implemented for all depositions in this work unless otherwise specified.

In situ and ex situ ellipsometry. The optical properties of the deposited layers were measured using an M-2000x spectroscopic ellipsometer (J. A. Woollam Co. Inc., $\lambda=246-1000 \mathrm{~nm}$ ). For in situ measurements, a custom reactor lid with fused silica viewports was used to collect ellipsometry information (Psi and Delta), measuring the centerregion of the large-area reactor. The raw ellipsometry data were fitted using various methods (Supporting Information, Section II). Full wafer thickness mapping. The thickness and refractive index $(\lambda=633 \mathrm{~nm})$ of the ZIF-8 layers deposited on $200 \mathrm{~mm}$ wafers were measured with a KLA-Tencor ASET F5x thin film measurement system equipped with a motorized stage. A radial map of Psi and Delta $(\lambda=400-800 \mathrm{~nm})$ was recorded for 100 points evenly distributed over the wafer and processed using the appropriate optical model. Methanol ellipsometric porosimetry. The samples were placed inside a custom porosimetry chamber equipped with an ellipsometer (Sentech $\mathrm{SE} 801, \lambda=350-850 \mathrm{~nm}$ ) and a programmable adsorbate dosing platform. Data were recorded at room temperature, with an equilibration time of $30 \mathrm{~s}$ for each data point.

QCM monitoring. The change in mass of the deposited film was monitored via a QCM setup integrated into the reactor lid. Au-coated AT-cut quartz crystals (Inficon, fundamental frequency $\sim 6 \mathrm{MHz}$ ) were used. Frequencies (590 data points per second) were recorded using an Inficon STM2 QCM monitoring system. The Sauerbrey equation was employed to estimate the mass increase from the change in frequency. ${ }^{65}$ The in-house developed thermal insulation cover resulted in a QCM stabilization time of approximately 1 hour, which was respected for all experiments.

Atomic Force Microscopy (AFM). AFM Imaging. Topography images $(6 \mu \mathrm{m} \times 6 \mu \mathrm{m}$ and $2 \mu \mathrm{m} \times 2 \mu \mathrm{m}, 1024 \times$ 1024 pixels) were recorded in intermittent contact mode with a PicoSPM 5500 (Agilent Technologies) setup in ambient conditions using Si cantilevers (OLYMPUS, AC160TS-R3). Data analysis was performed using WSXM 
5.0 software. ${ }^{66}$ Conductive AFM. A Bruker's Dimension Icon AFM system was used to check for pinholes in films deposited under standard and humidified conditions on Si substrates. The samples were electrically contacted with Ag paint using a custom sample holder. A heavily doped full diamond tip was used to test the samples with an applied DC bias voltage of $8.0 \mathrm{~V}$ at a scan speed of $0.5 \mathrm{~Hz}$. The threshold bias voltage for the standard MOF-CVD ZIF-8 coating was determined to be $>5.0 \mathrm{~V}$. All measurements were carried out in a glove box under an Ar atmosphere.

$X$-ray diffraction $(X R D)$ and reflectivity. Measurements were performed on a Malvern PANalytical Empyrean diffractometer equipped with a PIXcel3D solid-state detector using a $\mathrm{Cu}$ anode. Before each measurement, an iterative scheme was employed to optimize both sample height and tilt. $X$-ray reflectivity. Data were collected between incident angles of $-0.03^{\circ}$ and $4.5^{\circ}$ with a step size of $0.005^{\circ}$ and a counting time of $8.8 \mathrm{~s}$. Grazing incidence-XRD. Diffraction patterns were recorded in reflection geometry (incident beam angle $0.02^{\circ}$ ) within a $5^{\circ}-45^{\circ} 2 \theta$ range, using a step size of $0.053^{\circ}$ and a counting time of $1000 \mathrm{~s}$ per step. On the incident beam side, a $1 / 16^{\circ}$ fixed antiscatter slit was used to limit the divergence of the beam. Synchrotron GI-XRD. The measurements were conducted at the ID10-EH beamline of the European Synchrotron Radiation Facility (ESRF) in Grenoble, France and the XRD1 beamline of the Elettra Synchrotron in Trieste, Italy. Synchrotron GI-Wide-Angle X-ray Scattering (WAXS). These measurements were collected at the Austrian beamline at the Elettra Synchrotron. The collected two-dimensional data were processed using GIDVis. ${ }^{67}$

Ion beam analysis. Time-of-flight Elastic Recoil Detection Analysis (ToF-ERDA). A 6SDH Pelletron particle accelerator (National Electrostatics Corporation) equipped with an $8.0 \mathrm{MeV}^{35} \mathrm{Cl}^{4+}$ primary ion beam was used. The areal density (atoms $\mathrm{cm}^{-2}$ ) and elemental composition of the ALD ZnO coating on Si substrates were measured at a scattering angle and sample tilt of $40.5^{\circ}$ and $10^{\circ}$, respectively. The same recoil signals were considered for all elements except for $\mathrm{Zn}$, where the scattered $\mathrm{Cl}$ signal was used. After instrument calibration, the effect of elemental losses resulting from interactions between the sample and the ion beam was considered negligible. Rutherford Back Scattering $(R B S)$ was used to determine the metal density of the oxide precursor using a He-beam with an energy of $1.523 \mathrm{MeV}$ and a beam current of $45 \mathrm{nA}$. The scattering and tilt angles were set to $170^{\circ}$ and $11^{\circ}$, respectively.

X-ray Photoelectron Spectroscopy (XPS). XPS data for the ALD ZnO and MOF-CVD ZIF-8 films were collected using a PHI5600 Versaprobe II (Physical Electronics) utilizing a Al K $\alpha$ monochromatic X-ray source (1486.71 eV photon energy) with a beam irradiation power of $25 \mathrm{~W}$. The kinetic energy of the photoelectrons was measured with a take-off angle of $45^{\circ}$ and with a spot diameter of $100 \mu \mathrm{m}$ to measure surface compositions up to $\sim 5 \mathrm{~nm}$ in depth. The vacuum in the analysis chamber was below $1 \times 10^{-9}$ Torr during measurements. Survey scans were recorded with a pass energy of $187.85 \mathrm{eV}$ and an energy step size of $0.1 \mathrm{eV}$. After identification of the elements of interest using PHI Multipak software (v9.5), high-resolution scans of Zn 2p, C 1s, O 1s, and N 1s were obtained with a pass energy of $23.5 \mathrm{eV}$ and with an energy step size of $0.05 \mathrm{eV}$. Dual-beam charge neutralization was used to compensate 
for potential charging effects. The analysis and fitting were performed using CasaXPS software (Casa Software, Ltd.) employing a mixed Gaussian-Lorentzian peak shape and a Shirley type background. The probe depths for the films was found to be $3-5 \mathrm{~nm}$, calculated by multiplying the inelastic mean free path (IMFP) to three and to the cosine of the measurement angle for every electron energy of interest. The IMFP was evaluated using the Tanuma, Powel, and Penn (TPP-2M) relation. ${ }^{68}$

Infrared spectroscopy. A Varian 670 FTIR spectrometer with a Ge crystal plate in the Veemax III module, operated on attenuated total reflection geometry, was used. The IR spectra of the films deposited on Au-coated Si substrates were obtained using the actively cooled mercury cadmium telluride detector.

Time-of-flight secondary ion mass spectroscopy (ToF-SIMS). The samples at different MOF-CVD growth stages were probed using a TOF.SIMS 5 instrument (ION-TOF GmbH). A $30 \mathrm{keV} \mathrm{Bi}{ }_{3}^{+}$analysis beam was used in a highcurrent bunched mode for high mass resolution $\left(\mathrm{m} \Delta \mathrm{m}^{-1} \sim 8000\right.$ at $\left.29 \mathrm{u},{ }^{29} \mathrm{Si}^{+}\right)$. The primary ion dose was kept sufficiently low so that the static limit of $1 \times 10^{13}$ ions $\mathrm{cm}^{-2}$ per analysis was not exceeded. The pressure in the chamber was $\sim 3.4 \times 10^{-8}$ mbar during measurements. The accuracy of mass assignments, expressed as deviation (in ppm), is calculated by taking the difference between the experimental and theoretical mass of a fragment and dividing this number by the experimental mass. Deviations of $\leq 50 \mathrm{ppm}$ are indicative of satisfactory assignments. Depth profiles were obtained in a dual-beam configuration, where a $2.5 \mathrm{keV} \mathrm{Ar}_{1100}{ }^{+}$cluster ion beam was used as a sputter beam and $\mathrm{Bi}_{3}{ }^{+}$was used to analyze a $100 \mu \mathrm{m} \times 100 \mu \mathrm{m}$ area at the bottom of the $250 \mu \mathrm{m} \times 250 \mu \mathrm{m}$ crater.

Krypton physisorption. Using a Micromeritics 3Flex 3500 instrument, sorption measurements on the coatings have been performed as described in our previous work. ${ }^{12}$

Electron microscopy. Images were collected using a Philips XL30 FEG. Before imaging, the samples were coated with $5 \mathrm{~nm}$ of Pt.

Optical microscopy. An S lynx compact profilometer (Sensofar) was used to image HmIM particles. The images were acquired using a Nikon TU Plan Fluor lens with a magnification of $10 \times$ and $20 \times$ and subsequently processed using SensoSCAN.

Electrical characterization. A drop of a eutectic mixture of gallium and indium (EGaIn, 99.99 \%, Alfa Aesar) was used as the top electrical contact on MOF-CVD ZIF-8 films deposited on Pt-coated Si substrates. Current (I) was measured as a function of the applied bias (V) with the Pt bottom electrode contacted with Ag paint. At least $10 \mathrm{I}-\mathrm{V}$ curves were acquired at 5-10 different positions on the sample using a Yokogawa GS200 and a Keithley $6517 \mathrm{~B} / 2400$ as the voltage source and ammeter, respectively. The contact areas, ranging from $100 \times 10^{-6}$ to $400 \times$ 
$10^{-6} \mathrm{~cm}^{2}$, were estimated using a CCD camera. All instruments were controlled using custom software. The generated current density $(\mathrm{J})$ histograms were fitted using Gaussian functions for determining the peak center and width.

\section{AUTHOR INFORMATION}

\section{Corresponding Author}

*E-mail: rob.ameloot@,kuleuven.be

\section{Author Contributions}

A.J.C., I.S., and R.A. conceived and designed the experiments. A.J.C. carried out and analyzed all depositions and sample characterization, supported by all the authors. A.J.C. and I.S. developed the in situ monitoring protocols. A.J.C. and S.P. carried out XPS measurements and data analysis. K.M. and A.J.C. performed the ToF-SIMS measurements. V.R-G. and S.T. carried out the electrical characterization. The manuscript was written by A.J.C. under the guidance of I.S. and R.A., with input from all the co-authors. A.J.C. and I.S. contributed equally to this work. Correspondence and requests for materials should be addressed to R.A.

\section{Notes}

The authors declare no competing financial interest.

\section{ACKNOWLEDGMENTS}

This project has received funding from the European Research Council (ERC) under the European Union's (EU) Horizon 2020 research and innovation program (grant agreements $n^{\circ} 716472$ and 714122 with acronyms, VAPORE and Chem-fs-MOF, respectively). The Research Foundation-Flanders (FWO) is acknowledged for funding in the research projects G083016N, 1529618N, 1501618N, and the infrastructure projects from the Hercules Foundation G0H0716N, ZW13_07 and AKUL/09/42 - HER/09/021. I.S., T.H., R.V., and T.S. thank FWO for the fellowships 12L5417N, 1295317N, 1S00919N, and 1S53318N, respectively. S.T. thanks the Spanish Ministry of Economy and Commerce for his Ramón y Cajal fellowships (RYC-2016-19817). V.R.-G. is grateful for the predoctoral fellowship (FPU13/03203) awarded by the Spanish Ministry of Education, Culture, and Sports. A.J.C. acknowledges Silvia Armini, Jill Serron, Lennaert Wouters, Praveen Dara, Min Tu, Martin Obst, Cesar Parra Cabrera, Ann-Christin Dippel, and Oliver Feddersen-Clausen for scientific support. The authors acknowledge the European Synchrotron Radiation Facility (ESRF) for the provision of synchrotron radiation facilities and would like to thank Oleg Konovalov and Andrey Chumakov for the assistance in using beamline ID10-EH for GI-XRD experiments. A.J.C. 
and S.R.-H. are grateful to Prof. Roland Resel's group (TU Graz, Austria) for guidance in the data processing. This project has received funding from the EU-Horizon 2020 research and innovation program under grant agreement $\mathrm{n}^{\circ} 654360$ and 730872 having benefitted from the access provided by Elettra Synchrotron Trieste within the framework of the Nanoscience Foundries and Fine Analysis (NFFA) - Europe Transnational Access Activity (ID-462, ID-596, and ID-589) and CALIPSOplus (20190028). A.J.C. thank Heinz Amenitsch, Benedetta Marmiroli, Luisa Barba, and Giorgio Bais for assistance in using the Austrian SAXS-WAXS and XRD1 beamlines. The authors acknowledge DESY (Hamburg, Germany), a member of the Helmholtz Association HGF, for the provision of experimental facilities. Parts of this research were carried out at PETRA III and we would like to thank Michael Wharmby for assistance in using the P02.1 beamline (I-20180033 EC). Insights stemming from discussions with researchers in the field were enabled through COST Action MP1402 - Hooking together European research in Atomic Layer Deposition (HERALD), supported by COST (European Cooperation in Science and Technology).

\section{REFERENCES}

(1) Yang, D.; Gates, B. C. Catalysis by Metal-Organic Frameworks: Perspective and Suggestions for Future Research. ACS Catalysis 2019, 9 (3), 1779-1798.

(2) Ma, S.; Zhou, H.-C. Gas Storage in Porous Metal-Organic Frameworks for Clean Energy Applications. Chemical Communications 2010, 46 (1), 44-53.

(3) Kwon, H. T.; Jeong, H.-K.; Lee, A. S.; An, H. S.; Lee, J. S. Heteroepitaxially Grown Zeolitic Imidazolate Framework Membranes with Unprecedented Propylene/Propane Separation Performances. Journal of the American Chemical Society 2015, 137 (38), 12304-12311.

(4) Stassen, I.; Burtch, N.; Talin, A.; Falcaro, P.; Allendorf, M.; Ameloot, R. An Updated Roadmap for the Integration of Metal-Organic Frameworks with Electronic Devices and Chemical Sensors. Chemical Society Reviews 2017, 46 (11), 3185-3241.

(5) Allendorf, M. D.; Schwartzberg, A.; Stavila, V.; Talin, A. A. A Roadmap to Implementing Metal-Organic Frameworks in Electronic Devices: Challenges and Critical Directions. Chemistry - A European Journal 2011, 17 (41), 11372-11388.

(6) Wang, H.; Lustig, W. P.; Li, J. Sensing and Capture of Toxic and Hazardous Gases and Vapors by MetalOrganic Frameworks. Chemical Society Reviews 2018, 47 (13), 4729-4756.

(7) Yassine, O.; Shekhah, O.; Assen, A. H.; Belmabkhout, Y.; Salama, K. N.; Eddaoudi, M. $\mathrm{H}_{2} \mathrm{~S}$ Sensors: Fumarate-Based Fcu-MOF Thin Film Grown on a Capacitive Interdigitated Electrode. Angewandte Chemie International Edition 2016, 55 (51), 15879-15883.

(8) Stassen, I.; Bueken, B.; Reinsch, H.; Oudenhoven, J. F. M.; Wouters, D.; Hajek, J.; Van Speybroeck, V.; Stock, N.; Vereecken, P. M.; Van Schaijk, R.; et al. Towards Metal-Organic Framework Based Field Effect Chemical Sensors: UiO-66- $\mathrm{NH}_{2}$ for Nerve Agent Detection. Chemical Science 2016, 7 (9), 5827-5832. 
(9) Shekhah, O.; Eddaoudi, M. The Liquid Phase Epitaxy Method for the Construction of Oriented ZIF-8 Thin Films with Controlled Growth on Functionalized Surfaces. Chemical Communications 2013, 49 (86), 10079.

(10) Eslava, S.; Zhang, L.; Esconjauregui, S.; Yang, J.; Vanstreels, K.; Baklanov, M. R.; Saiz, E. Metal-Organic Framework ZIF-8 Films as Low-א Dielectrics in Microelectronics. Chemistry of Materials 2013, 25 (1), $27-33$.

(11) Krishtab, M.; Stassen, I.; Stassin, T.; Cruz, A. J.; Okudur, O. O.; Armini, S.; Wilson, C.; De Gendt, S.; Ameloot, R. Vapor-Deposited Zeolitic Imidazolate Frameworks as Gap-Filling Ultra-Low-k Dielectrics. Nature Communications 2019, 10 (1), 3729.

(12) Stassen, I.; Styles, M.; Grenci, G.; Gorp, H. V.; Vanderlinden, W.; Feyter, S. D.; Falcaro, P.; Vos, D. D.; Vereecken, P.; Ameloot, R. Chemical Vapour Deposition of Zeolitic Imidazolate Framework Thin Films. Nature Materials 2016, 15 (3), 304-310.

(13) Lew, C. M.; Cai, R.; Yan, Y. Zeolite Thin Films: From Computer Chips to Space Stations. Accounts of Chemical Research 2010, 43 (2), 210-219.

(14) Ozaydin-Ince, G.; Coclite, A. M.; Gleason, K. K. CVD of Polymeric Thin Films: Applications in Sensors, Biotechnology, Microelectronics/Organic Electronics, Microfluidics, MEMS, Composites, and Membranes. Reports on Progress in Physics 2012, 75 (1), 016501.

(15) Ahvenniemi, E.; Karppinen, M. Atomic/Molecular Layer Deposition: A Direct Gas-Phase Route to Crystalline Metal-Organic Framework Thin Films. Chemical Communications 2016, 52 (6), 1139-1142.

(16) Ahvenniemi, E.; Karppinen, M. In Situ Atomic/Molecular Layer-by-Layer Deposition of Inorganic-Organic Coordination Network Thin Films from Gaseous Precursors. Chemistry of Materials 2016, 28 (17), 6260-6265.

(17) Tanskanen, A.; Karppinen, M. Iron-Terephthalate Coordination Network Thin Films through in-Situ Atomic/Molecular Layer Deposition. Scientific Reports 2018, 8 (1), 8976.

(18) Medishetty, R.; Zhang, Z.; Sadlo, A.; Cwik, S.; Peeters, D.; Henke, S.; Mangayarkarasi, N.; Devi, A. Fabrication of Zinc-Dicarboxylate- and Zinc-Pyrazolate-Carboxylate-Framework Thin Films through VapourSolid Deposition. Dalton Transactions 2018, 47 (40), 14179-14183.

(19) Lausund, K. B.; Nilsen, O. All-Gas-Phase Synthesis of UiO-66 through Modulated Atomic Layer Deposition. Nature Communications 2016, 7, 13578.

(20) Lausund, K. B.; Petrovic, V.; Nilsen, O. All-Gas-Phase Synthesis of Amino-Functionalized UiO-66 Thin Films. Dalton Transactions 2017, 46 (48), 16983-16992.

(21) Salmi, L. D.; Heikkilä, M. J.; Puukilainen, E.; Sajavaara, T.; Grosso, D.; Ritala, M. Studies on Atomic Layer Deposition of MOF-5 Thin Films. Microporous and Mesoporous Materials 2013, 182, 147-154.

(22) Salmi, L. D.; Heikkilä, M. J.; Vehkamäki, M.; Puukilainen, E.; Ritala, M.; Sajavaara, T. Studies on Atomic Layer Deposition of IRMOF-8 Thin Films. Journal of Vacuum Science \& Technology A 2014, 33 (1), $01 \mathrm{~A} 121$. 
(23) Tynell, T.; Karppinen, M. Atomic Layer Deposition of ZnO: A Review. Semiconductor Science and Technology 2014, 29 (4), 043001.

(24) Khaletskaya, K.; Turner, S.; Tu, M.; Wannapaiboon, S.; Schneemann, A.; Meyer, R.; Ludwig, A.; Van Tendeloo, G.; Fischer, R. A. Self-Directed Localization of ZIF-8 Thin Film Formation by Conversion of ZnO Nanolayers. Advanced Functional Materials 2014, 24 (30), 4804-4811.

(25) Park, K. S.; Ni, Z.; Cote, A. P.; Choi, J. Y.; Huang, R.; Uribe-Romo, F. J.; Chae, H. K.; O’Keeffe, M.; Yaghi, O. M. Exceptional Chemical and Thermal Stability of Zeolitic Imidazolate Frameworks. Proceedings of the National Academy of Sciences 2006, 103 (27), 10186-10191.

(26) Li, W.; Su, P.; Li, Z.; Xu, Z.; Wang, F.; Ou, H.; Zhang, J.; Zhang, G.; Zeng, E. Ultrathin Metal-Organic Framework Membrane Production by Gel-Vapour Deposition. Nature Communications 2017, 8 (1).

(27) Young, C.; Wang, J.; Kim, J.; Sugahara, Y.; Henzie, J.; Yamauchi, Y. Controlled Chemical Vapor Deposition for Synthesis of Nanowire Arrays of Metal-Organic Frameworks and Their Thermal Conversion to Carbon/Metal Oxide Hybrid Materials. Chemistry of Materials 2018, 30 (10), 3379-3386.

(28) Xu, P.; Liu, M.; Li, X.; Xu, T.; Zhang, Y. Multi-Dimensional Multi-Level Sensing Nanostructure for HighPerformance Detection to Trace-Level Dopamine Molecules. In 2017 19th International Conference on Solid-State Sensors, Actuators and Microsystems (TRANSDUCERS); 2017; pp 762-765.

(29) Ma, X.; Kumar, P.; Mittal, N.; Khlyustova, A.; Daoutidis, P.; Mkhoyan, K. A.; Tsapatsis, M. Zeolitic Imidazolate Framework Membranes Made by Ligand-Induced Permselectivation. Science 2018, 361 (6406), $1008-1011$.

(30) Jiménez, P.; Roux, M. V.; Turrión, C. Thermochemical Properties of N-Heterocyclic Compounds IV. Enthalpies of Combustion, Vapour Pressures and Enthalpies of Sublimation, and Enthalpies of Formation of 2-Methylimidazole and 2-Ethylimidazole. The Journal of Chemical Thermodynamics 1992, 24 (11), 11451149.

(31) Coclite, A. M.; Howden, R. M.; Borrelli, D. C.; Petruczok, C. D.; Yang, R.; Yagüe, J. L.; Ugur, A.; Chen, N.; Lee, S.; Jo, W. J.; et al. 25th Anniversary Article: CVD Polymers: A New Paradigm for Surface Modification and Device Fabrication. Advanced Materials 2013, 25 (38), 5392-5423.

(32) Gleason, K. K. CVD Polymers: Fabrication of Organic Surfaces and Devices; Wiley-VCH Verlag GmbH \& Co.: Weinheim, 2015.

(33) Rocklein, M. N.; George, S. M. Temperature-Induced Apparent Mass Changes Observed during Quartz Crystal Microbalance Measurements of Atomic Layer Deposition. Analytical Chemistry 2003, 75 (19), 4975-4982.

(34) Riha, S. C.; Libera, J. A.; Elam, J. W.; Martinson, A. B. F. Design and Implementation of an Integral WallMounted Quartz Crystal Microbalance for Atomic Layer Deposition. Review of Scientific Instruments 2012, 83 (9), 094101.

(35) Mackus, A. J. M.; MacIsaac, C.; Kim, W.-H.; Bent, S. F. Incomplete Elimination of Precursor Ligands during Atomic Layer Deposition of Zinc-Oxide, Tin-Oxide, and Zinc-Tin-Oxide. The Journal of Chemical Physics 2016, 146 (5), 052802. 
(36) Weckman, T.; Laasonen, K. Atomic Layer Deposition of Zinc Oxide: Diethyl Zinc Reactions and Surface Saturation from First-Principles. The Journal of Physical Chemistry C 2016, 120 (38), 21460-21471.

(37) Ginley, D. S., Hosono, H., Paine, D. C. Handbook of Transparent Conductors; Springer: New York, 2010.

(38) Stassen, I.; De Vos, D.; Ameloot, R. Vapor-Phase Deposition and Modification of Metal-Organic Frameworks: State-of-the-Art and Future Directions. Chemistry - A European Journal 2016, 22 (41), 1445214460.

(39) Tao, J.; Wang, X.; Sun, T.; Cai, H.; Wang, Y.; Lin, T.; Fu, D.; Ting, L. L. Y.; Gu, Y.; Zhao, D. Hybrid Photonic Cavity with Metal-Organic Framework Coatings for the Ultra-Sensitive Detection of Volatile Organic Compounds with High Immunity to Humidity. Scientific Reports 2017, 7, 41640.

(40) Esken, D.; Noei, H.; Wang, Y.; Wiktor, C.; Turner, S.; Van Tendeloo, G.; Fischer, R. A. ZnO@ZIF-8: Stabilization of Quantum Confined ZnO Nanoparticles by a Zinc Methylimidazolate Framework and Their Surface Structural Characterization Probed by $\mathrm{CO}_{2}$ Adsorption. Journal of Materials Chemistry 2011, 21 (16), 5907.

(41) Kalidindi, S. B.; Esken, D.; Fischer, R. A. B-N Chemistry@ZIF-8: Dehydrocoupling of Dimethylamine Borane at Room Temperature by Size-Confinement Effects. Chemistry - A European Journal 2011, 17 (24), 6594-6597.

(42) Tu, M.; Reinsch, H.; Rodríguez-Hermida, S.; Verbeke, R.; Stassin, T.; Egger, W.; Dickmann, M.; Dieu, B.; Hofkens, J.; Vankelecom, I. F. J.; et al. Reversible Optical Writing and Data Storage in an AnthraceneLoaded Metal-Organic Framework. Angewandte Chemie 2019, 131 (8), 2445-2449.

(43) Campagnol, N.; Stassen, I.; Binnemans, K.; de Vos, D. E.; Fransaer, J. Metal-Organic Framework Deposition on Dealloyed Substrates. Journal of Materials Chemistry A 2015, 3 (39), 19747-19753.

(44) Zhang, K.; Lively, R. P.; Dose, M. E.; Brown, A. J.; Zhang, C.; Chung, J.; Nair, S.; Koros, W. J.; Chance, R. R. Alcohol and Water Adsorption in Zeolitic Imidazolate Frameworks. Chemical Communications 2013, $49(31), 3245-3247$.

(45) Avrami, M. Kinetics of Phase Change. II. Transformation-time Relations for Random Distribution of Nuclei. The Journal of Chemical Physics 1940, 8 (2), 212-224.

(46) Avrami, M. Kinetics of Phase Change. I. General Theory. The Journal of Chemical Physics 1939, 7 (12), 1103-1112.

(47) Avrami, M. Granulation, Phase Change, and Microstructure. Kinetics of Phase Change. III. The Journal of Chemical Physics 1941, 9 (2), 177-184.

(48) Gualtieri, A. F. Synthesis of Sodium Zeolites from a Natural Halloysite. Physics and Chemistry of Minerals 2001, 28 (10), 719-728.

(49) Bueken, B.; Reinsch, H.; Heidenreich, N.; Vandekerkhove, A.; Vermoortele, F.; Kirschhock, C. E. A.; Stock, N.; De Vos, D.; Ameloot, R. An in Situ Investigation of the Water-Induced Phase Transformation of UTSA-74 to MOF-74(Zn). CrystEngComm 2017, 19 (29), 4152-4156. 
(50) Patterson, J. P.; Abellan, P.; Denny, M. S.; Park, C.; Browning, N. D.; Cohen, S. M.; Evans, J. E.; Gianneschi, N. C. Observing the Growth of Metal-Organic Frameworks by in Situ Liquid Cell Transmission Electron Microscopy. Journal of the American Chemical Society 2015, 137 (23), 7322-7328.

(51) Osta, R. E.; Feyand, M.; Stock, N.; Millange, F.; Walton, R. I. Crystallisation Kinetics of Metal-Organic Frameworks from in Situ Time-Resolved X-Ray Diffraction. Powder Diffraction 2013, 28 (S2), S256S275.

(52) Ahnfeldt, T.; Moellmer, J.; Guillerm, V.; Staudt, R.; Serre, C.; Stock, N. High-Throughput and Time-Resolved Energy-Dispersive X-Ray Diffraction (EDXRD) Study of the Formation of CAU-1-(OH $)_{2}$ : Microwave and Conventional Heating. Chemistry - A European Journal 2011, 17 (23), 6462-6468.

(53) Millange, F.; Medina, M. I.; Guillou, N.; Férey, G.; Golden, K. M.; Walton, R. I. Time-Resolved in Situ Diffraction Study of the Solvothermal Crystallization of Some Prototypical Metal-Organic Frameworks. Angewandte Chemie International Edition 2010, 49 (4), 763-766.

(54) Jeong, T. H.; Kim, M. R.; Seo, H.; Kim, S. J.; Kim, S. Y. Crystallization Behavior of Sputter-Deposited Amorphous $\mathrm{Ge}_{2} \mathrm{Sb}_{2} \mathrm{Te}_{5}$ Thin Films. Journal of Applied Physics 1999, 86 (2), 774-778.

(55) Bass, J. D.; Grosso, D.; Boissiere, C.; Sanchez, C. Pyrolysis, Crystallization, and Sintering of Mesostructured Titania Thin Films Assessed by in Situ Thermal Ellipsometry. Journal of the American Chemical Society 2008, 130 (25), 7882-7897.

(56) Yeung, H. H.-M.; Sapnik, A. F.; Massingberd-Mundy, F.; Gaultois, M. W.; Wu, Y.; Fraser, D. A. X.; Henke, S.; Pallach, R.; Heidenreich, N.; Magdysyuk, O. V.; et al. Control of Metal-Organic Framework Crystallization by Metastable Intermediate Pre-equilibrium Species. Angewandte Chemie International Edition 2019, 58 (2), 566-571.

(57) Newberg, J. T.; Goodwin, C.; Arble, C.; Khalifa, Y.; Boscoboinik, J. A.; Rani, S. ZnO(1010) Surface Hydroxylation under Ambient Water Vapor. The Journal of Physical Chemistry B 2018, 122 (2), 472-478.

(58) Cliffe, M. J.; Mottillo, C.; Stein, R. S.; Bučar, D.-K.; Friščić, T. Accelerated Aging: A Low Energy, SolventFree Alternative to Solvothermal and Mechanochemical Synthesis of Metal-Organic Materials. Chemical Science 2012, 3 (8), 2495-2500.

(59) Shi, Q.; Chen, Z.; Song, Z.; Li, J.; Dong, J. Synthesis of ZIF-8 and ZIF-67 by Steam-Assisted Conversion and an Investigation of Their Tribological Behaviors. Angewandte Chemie International Edition 2011, 50 (3), 672-675.

(60) Mottillo, C.; Lu, Y.; Pham, M.-H.; Cliffe, M. J.; Do, T.-O.; Friščić, T. Mineral Neogenesis as an Inspiration for Mild, Solvent-Free Synthesis of Bulk Microporous Metal-Organic Frameworks from Metal (Zn, Co) Oxides. Green Chemistry 2013, 15 (8), 2121-2131.

(61) Taek Kwon, H.; Jeong, H.-K.; S. Lee, A.; Seong An, H.; Lee, T.; Jang, E.; Suk Lee, J.; Choi, J. DefectInduced Ripening of Zeolitic-Imidazolate Framework ZIF-8 and Its Implication to Vapor-Phase Membrane Synthesis. Chemical Communications 2016, 52 (78), 11669-11672. 
(62) Stassin, T.; Rodríguez-Hermida, S.; Schrode, B.; Cruz, A. J.; Carraro, F.; Kravchenko, D.; Creemers, V.; Stassen, I.; Hauffman, T.; Vos, D. D.; et al. Vapour-Phase Deposition of Oriented Copper Dicarboxylate Metal-Organic Framework Thin Films. Chemical Communications 2019, 55 (68), 10056-10059.

(63) Vahlas, C.; Caussat, B.; Senocq, F.; Gladfelter, W. L.; Aloui, L.; Moersch, T. A Delivery System for Precursor Vapors Based on Sublimation in a Fluidized Bed. Chemical Vapor Deposition 2007, 13 (2-3), 123129.

(64) Vahlas, C.; Caussat, B.; Gladfelter, W.; Senocq, F.; Gladfelter, E. Liquid and Solid Precursor Delivery Systems in Gas Phase Processes. Recent Patents on Materials Science 2015, 8 (2), 91-108.

(65) Sauerbrey, G. Verwendung von schwingquarzen zur wägung dünner schichten und zur mikrowägung. Zeitschrift für Physik 1959, 155 (2), 206-222.

(66) Horcas, I.; Fernández, R.; Gómez-Rodríguez, J. M.; Colchero, J.; Gómez-Herrero, J.; Baro, A. M. WSXM: A Software for Scanning Probe Microscopy and a Tool for Nanotechnology. Review of Scientific Instruments 2007, 78 (1), 013705.

(67) Schrode, B.; Pachmajer, S.; Dohr, M.; Röthel, C.; Domke, J.; Fritz, T.; Resel, R.; Werzer, O. GIDVis: A Comprehensive Software Tool for Geometry-Independent Grazing-Incidence X-Ray Diffraction Data Analysis and Pole-Figure Calculations. Journal of Applied Crystallography 2019, 52 (3), 683-689.

(68) Tanuma, S.; Powell, C. J.; Penn, D. R. Calculation of electron inelastic mean free paths (IMFPs) VII. Reliability of the TPP-2M IMFP predictive equation. Surface and Interface Analysis 2003, 35 (3), 268-275. 


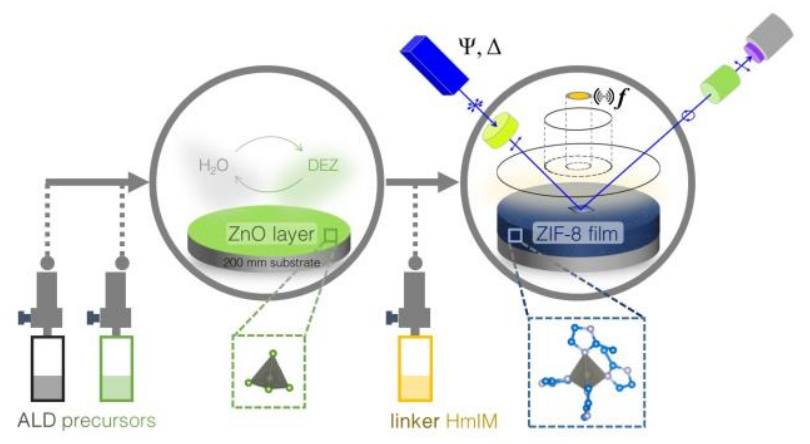

